\title{
Research on Causes and Suggestions of the Difficulty of Reimbursement in the Financial Affairs of the Institutions of Higher Learning
}

\author{
Chen Yuanchao \\ China West Normal University \\ Nanchong, Sichuan, 637009
}

\begin{abstract}
With the increase of state's spending on colleges and universities, the institutional revenue of higher education, especially the scientific research funds, keeps increasing, which makes the source of funds present the trend of diversification and the work of financial accounting in colleges and universities more and more strict and onerous. However, the number of accounting personnel does not match with their workload, thus making the problem of "the difficulty of reimbursement" more and more prominent in institutions of higher learning. This paper aims to analyze and explore the causes of the difficulty of reimbursement in institutions of higher learning from the perspective of a financial worker in colleges and universities. By applying such methods as intensifying information construction in financial affairs, actively investing in the development and usage of online appointment reimbursement system, fully implementing the system of financial information officer and further simplifying financial examination and approval procedure, " the difficulty of reimbursement" in institutions of higher learning can be solved effectively.
\end{abstract}

Keywords-financial affairs in the institutions of higher learning, the difficulty of reimbursement, causes and suggestions

\section{INTRODUCTION}

At present, with the increase of state's spending on colleges and universities, the institutional revenue of higher education, especially the scientific research funds, keeps increasing, which makes the source of funds present the trend of diversification and the work of financial accounting in colleges and universities more and more strict and onerous. The flow of capital increases with each passing day, the work of financial affairs is onerous, personnel allocation on audit post is inadequate and inappropriate, the conflicts and problems come to be increasingly severe in the process of audit, work efficiency is low and the allocation of financial personnel cannot increase with year-on-year growth of the size of expenditure, therefore, the problem of "the difficulty of reimbursement" arises[1]. Although accounting computerization has come into real in the financial system in institutions of higher learning, which, to some extent, improves the efficiency of reimbursement, "the difficulty of reimbursement" has not been resolved fundamentally. Faculty staff often complain about the difficulty to reimburse and the head of financial department is often called to interview with the leaders of colleges, therefore, how to optimize examination and approval procedure, improve the efficiency of financial reimbursement, enhance service quality and solve "the difficulty of reimbursement" is the key point as well as the difficult point to reform financial management in institutions of higher learning in recent years.

\section{CAUSE ANALYSIS OF THE DIFFICULTY OF FINANCIAL REIMBURSEMENT IN INSTITUTIONS OF HIGHER LEARNING}

\section{A. Multiple examination and approval procedures for financial reimbursement}

It's regulated in the financial affair of institutions of higher learning that the system of "one pen" should be carried out in the management of all expenditure in institution of higher learning, which means that the heads of institutions, teaching auxiliary offices and secondary schools are in full charge of the signature, examination and approval in their own departments. As we all know, the heads of each departments are busy in teaching and scientific research. It is usually in vain to look for leaders to sign. Besides regular expenditure, there are many special funds such as scientific research funds, expenditure on discipline construction, government procurement, infrastructure projects, etc. which require corresponding leaders in office of research affairs, office of teaching affairs, graduate school, office of state-owned assets and equipment management and other departments to examine and approve. And it requires college leaders who are in charge of relevant offices and financial affairs or even the principals to sign if the amount exceeds a certain limit, finally succeeding in reimbursement after looking for the leader of finance office to sign. In the eyes of the people who need to reimburse, it is actually the expenditure in their own departments and should be very easy to reimburse. However, it has to undergo several examinations and approvals. In a fiscal year, they go to finance office to reimburse where they hardly go, only to be told to fill various forms. More often than not, it is an unknown financial audit personnel who "command" them to do everything, which makes them very uncomfortable, believing that it is very difficult to reimburse. The complicated examination and approval procedures considerably increase the time to reimburse, have a severe impact on the efficiency of financial reimbursement and cause negative emotion, thus they often complain about the procedures of examination and approval in the process of reimbursement and are unkind to financial staff of finance office. 


\section{B. Unfixed personnel to do the work of reimbursement and information asymmetry}

The financial affairs in institutions of higher learning mainly include "revenue", "expenditure" and "balance", among which "expenditure" is a critical part in the management of the expenditure of colleges. It is very easy to pay to finance office but extremely hard to reimburse from it in the eyes of people who need to reimburse. At present, we often meet some newlyrecruited persons in reimbursement hall in finance department, which fully shows that the people who are in charge of reimbursement are numerous and unfixed with great mobility. They know less about financial expertise which brings many problems for financial audit personnel to publicize explain and guide the financial reimbursement[2]. In addition, with the continuous adjustment and perfection on financial policy by our state, the regulations of colleges and universities also keep changing and revising with it. As for financial personnel who are responsible for the task of reimbursement in finance office, they may fail to get to know new policies and regulations and make mistakes in some receipts in the process of reimbursement, causing the unsuccessful reimbursement. Such information asymmetry make the people who need to reimburse misunderstand finance department, thus influencing its whole image.

\section{The concentration of time for faculty to reimburse}

Because of the particularity of institutions of higher learning, many faculty and students in colleges and universities choose to reimburse in the beginning of semesters, in the end of semesters, in the conclusion of their research projects at the end of years or when they are urged by finance office to report expenditure schedule[3]. The faculty are usually occupied by teaching and research in their daily work and think there is a long time before expense write-off in school, so many of them reimburse in no hurry. Instead, they reimburse to finance department at one-time after they accumulate certain amount of receipts. Therefore, the time they reimburse usually centers on the next half year when finance department is busy in examining and urging each unit in colleges to accelerate the execution progress of their budget, in various reimbursement and in making every kind of statements, budgets of next year, etc. Therefore, due to the concentration of the time to reimburse, the "scene" of lining up to wait for reimbursement is often seen in the reimbursement hall.

\section{The service and concept of audit personnel in financial department needed to be improved}

For a long time, financial personnel are always the passive "receiver", which means that they wait for the people who bring receipts to reimburse in their office. New accounting system brings a huge challenge to financial department. Because financial personnel also need to study and digest this new system, let alone the people in charge of reimbursement who are not familiar with or know nothing about new system. Such information asymmetry reinforces their dissatisfactory on financial department. Financial personnel treat themselves as a complete administrator as well as a manager, showing impatient to those whose receipts have "problems" such as unreasonable reimbursement, incomplete procedures of signature, etc. And they do not explain in detail to the people who need to reimburse where are the problems and which leaders need to sign and so forth, thus making them shuttle between reimbursement hall and their own units. Their precious time is taken away in such a ruthless manner. Meanwhile the failure of transfer caused by some mistakes in transfer number, name of unit or opening bank is not released in time because of the limited financial personnel, making many of them think why they haven't yet received money after handing in these receipts for several weeks or even several months? They always take for granted that the efficiency of financial office is low. However, financial office is often mistaken by the people who need to reimburse due to the mistakes of transfer information.

\section{WAYS AND SUGGESTIONS TO SOLVE THE DIFFICULTY OF REIMBURSEMENT IN INSTITUTIONS OF HIGHER LEARNING}

\section{A. Actively implement online appointment reimbursement system and speeding up to promote the information construction of finance in institutions of higher learning}

Financial management system in institutions of higher learning can connect with banks, achieving the direct connection between banks and colleges. Based on existing technological level and maturity of financial system in institutions of higher learning, online appointment reimbursement system of "No waiting" can be developed. In addition, financial department can coordinate with operating departments to provide financial information enquiry in time and make access to self-services such as the enquiry of research projects funds, the self-service enquiry of tuition and overdue fee for students and the enquiry of housing funds for faculties[4]. By applying online appointment reimbursement system of "No waiting", those who need to reimburse can fill forms and submit them in the system of online appointment reimbursement as long as you can access to Internet, and keep track of reimbursement progress. After the examination and approval of financial personnel, the reimbursement sum can be directly transferred to their accounts by online banks without lining up to wait for submitting receipts, which effectively solves the conflicts caused by the direct connection between those who need to reimburse and financial personnel and improves the work efficiency of financial personnel.

\section{B. Optimize the procedure of financial examination and approval}

It is suggested that leadership in institutions of higher learning should optimize and improve the procedure of financial examination and approval in an appropriate manner. It is suggested that each secondary units should assign or authorize an administrator with more time working in office to sign in order to ensure that the signature can be done in time. From the perspective of colleges, financial office should delegate its authority properly. The author holds that the authority of examination and approval can be delegate to each secondary unit which means that there is no need to sign by financial office so long as it is the budgetary funds. The adjustment can also be made in financial office. As the" God of Wealth" of in institutions of higher learning, financial office 
plays a pivotal role in institutions of higher learning and the heads of it have lots of meetings to attend with few time in office, so it is very difficult to find the head of the office to sign. And it requires colleges to finish various budgets made at the beginning of the year in a fiscal year to ensure that each funds can be executed properly. Therefore, it is suggested that heads in financial department should delegate certain authority of examination and approval to section chief (for instance, if the sum of reimbursement is lower than 50,000 Yuan, the heads can authorize examination and approval to section chief) in order to make those who go to financial department to find heads to sign satisfy. Of course, the best way is to implement online appointment reimbursement. Only by doing so, they need not to shuttle among different departments and can directly follow the operation process and leaders of financial department, operation department and colleges can sign online.

\section{Implement the system of financial information officer in an all-round manner}

The financial department can strive for the support of leaders of colleges to implement the system of financial information officer (full time) in an all-round manner in all secondary units of the whole school, which means that each secondary unit recommends a regular staff to responsible for the reimbursement of faculty in its own unit. Their main duty is to publicize relevant financial policies, laws and regulations of state, province and school, collect receipts of reimbursement of its own unit to make a preliminary examination, return the wrong receipts to handlers and tell them how to fill forms in order to prevent them from shuttling between their own units and financial department[2]. And the social benefits of these staff should also be attached great importance, including promotion and professional title appraisal. Trained by financial department, they study the knowledge of financial reimbursement on a regular or irregular basis, give full play to their potential and function as a financial information officer and serve as a bridge between people who need to reimburse and financial department.

\section{Guide faculty and students to manage the time of reimbursement properly}

In order to solve the problem of the concentration of reimbursement and relieve the overload work of financial personnel, financial department can take appropriate measures to alleviate the press of reimbursement. As for most colleges and universities, the peak period of reimbursement is usually in November and December. Therefore, financial department can take diversion measures to alleviate the press of the concentration of reimbursement, treat the settlement of liquidation and collection of receipts as a regular work, consult with office of research affairs on the time of the conclusion of scientific research projects which can be arranged on off-peak period[3]. By guiding each secondary unit to decentralize their time of reimbursement, each budget schedule made in the beginning of the year can be executed properly and the congestion of reimbursement in the end of the year or the semesters can be avoided.

\section{E. Strengthen service awareness and build service-oriented organization}

1. Financial department need to change its service concept and strengthen its service awareness. Colleges and universities with good conditions can set up a separate place "where people can read information"(for instance various newspaper, magazines, etc.) next to reimbursement hall. And by having access to $\mathrm{Wi}-\mathrm{Fi}$, people who need to reimburse can amuse themselves and are even provided services like tea and water when they wait for reimbursement. High-quality service can strengthen faculty's understanding on the work of financial department.

2. Financial department need to visit each secondary units regularly or irregularly to listen to their needs, discuss collectively the problems they may encounter in the process of reimbursement and try to find solutions of "the difficulty of reimbursement". Financial department should collect information and form investigation report in light of the survey and research, thus publishing a booklet of service guide of financial reimbursement on the "the difficulty of reimbursement"

3. Financial department should strengthen the information construction of finance, publicize financial policies and relevant regulations on official website in order to make faculty get to know some new changes and new demands in financial policies in the first place and understand the difficulties of the work in financial department, which can win understandings and support from faculty on the work of financial department.

4. No-cash reimbursement should be implemented in an allround manner. Financial department should take full advantage of modern technology to transform cash payment into online payment. By using such way, the post of cashier can be reduced and various risks can be also reduced in the process of cash flow. More importantly, there is no need to hustle in financial department to wait for "money".

5. It should strengthen the study on financial knowledge in financial department. With the rapid development of economy and society, the competition among colleges and universities become intense, which require financial personnel to enhance their qualities. In addition to proficient professional expertise on finance, they need to know financial management. It is inevitable for institutions of higher learning to follow a road toward intensive management in financial management. Therefore, financial personnel need to keep updating their knowledge structure and adjust to the changing demand of new accounting system through multi-channel, multi-mode and multi-level training and learning, thus cultivating each of financial personnel into qualified comprehensive managerial staff.

\section{CONCLUSION}

"The difficulty of reimbursement" in institutions of higher learning mainly embodies in the lack of audit personnel with lots of work and great pressure. Plenty of time for reimbursement is wasted because those who need to reimburse do not update their information on existing financial system and policies. Therefore, the most effective way to solve "the 
difficulty of reimbursement" is to set up the position of financial information officer and apply online appointment reimbursement system. With the prevalence of financial knowledge, the simplification of procedures of examination and approval, continuous perfection of financial information construction and the enhancement of quantity and quality of financial personnel, the problem of "the difficulty of reimbursement" in institutions of higher learning will be solved properly.

\section{REFERENCES}

[1] Gan Yaqin. An Analysis on the Problem of "the Difficulty of Reimbursement" in the Finance of Institutions of Higher Learning[J] Contemporary Economics. 2016(10) (In Chinese)

[2] Zhong Zhengmin. Analysis on Reasons and Suggestion of "the Difficulty of Reimbursement" in the Finance of Institutions of Higher Learning[J] Modern Economic Information.2017(3) (In Chinese)

[3] Huang Hongjie. Study on the Causes and Suggestions of "the Difficulty of Reimbursement" in the Finance of Institutions of Higher Learning[J] Contemporary Economics. 2015(10) (In Chinese)

[4] Wu Jinghui. The Problems of Reimbursement in the Finance of Institutions of Higher Learning[J] Assets and Finances in Administration and Institution. 2013(2) (In Chinese) 